\title{
Working
}

Paper 


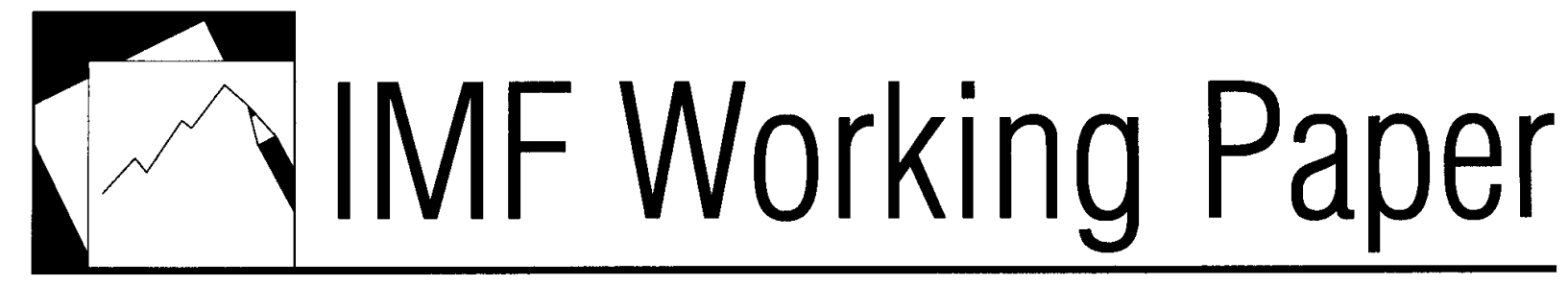

\section{Inflation Inertia in Egypt and its Policy Implications}

Kenji Moriyama 


\title{
IMF Working Paper
}

Middle East and Central Asia Department

\section{Inflation Inertia in Egypt and its Policy Implications \\ Prepared by Kenji Moriyama ${ }^{1}$}

Authorized for distribution by Ralph Chami

July 2011

\begin{abstract}
This paper investigates the degree of inflation inertia in Egypt and its determinants using the cross country data consisting of over 100 countries. Medium-unbiased estimator of inflation inertia in Egypt is high compared to other countries, as indicated by its location around the upper quartile among the sample. The cross country analysis indicates that counter-cyclical macroeconomic policy and fiscal consolidation are a key to reduce inflation inertia and the costs of disinflation.
\end{abstract}

JEL Classification Numbers: E31, E52, E58

Keywords: Inflation, monetary policy

Author's E-Mail Address:kmoriyama@imf.org

\section{This Working Paper should not be reported as representing the views of the IMF.}

The views expressed in this Working Paper are those of the author(s) and do not necessarily represent those of the IMF or IMF policy. Working Papers describe research in progress by the author(s) and are published to elicit comments and to further debate.

\footnotetext{
${ }^{1}$ The author is grateful for helpful comments from Alan MacArthur, Hassan Al-Atrash, Ralph Chami, and participants in the seminar held at the Central Bank of Egypt in January 2011.
} 
I. Introduction

II. Preliminary Discussions ..............................................................................................

A. Inflation Developments in Egypt-Recent developments and Cross Country

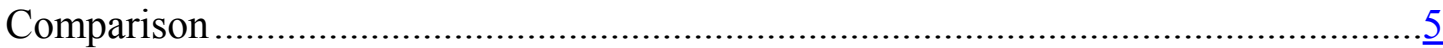

B. Why Is Inflation Inertia Important for Disinflation? ...................................... $\frac{6}{6}$

C. Empirical Literature on Inflation Inertia ....................................................... $\frac{7}{7}$

D. Inflation persistency in Emerging Market Countries-Conditional Inflation Derived from a Transition Matrix.........................................................................

III. Inflation Inertia in Egypt.................................................................................. 9

A. Measuring Inflation Inertia by the Reduced Form Model: Re-interpretation of the

Coefficient of Auto-regression Process by the Spectrum Analysis ........................... $\underline{9}$

B. Estimated Inflation Inertia in Egypt ........................................................ 10

IV. Determinants of Inflation Inertia-Cross Country Analysis .....................................11

A. Cross Country Comparison of Inflation Inertia ............................................ $\frac{11}{12}$

B. Investigating Determinants of Inflation Inertia-Model .................................. $\frac{12}{14}$

C. The Data and Methodology.................................................................... 14

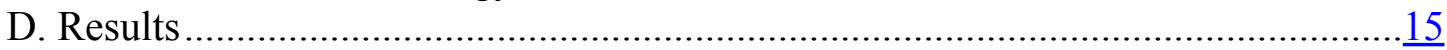

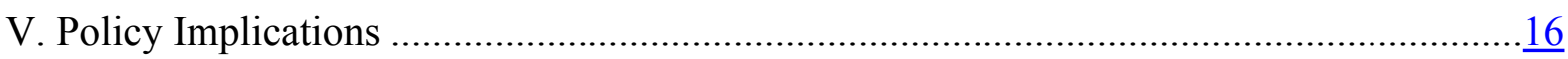

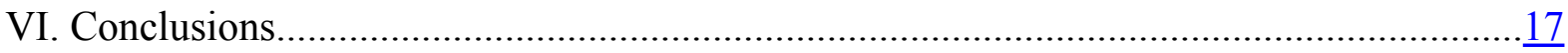

Tables

1. Statistics of the Distribution of Inflation for Countries with per Capita GDP (PPP base) from US\$6000 to 15,000 . .20

2. Emerging Market Countries: Transition Matrix, 1980-2009 ........................................21

3. Egypt: Estimated Headlines CPI Inflation (Monthly, Seasonally Adjusted) Intertia, 2000-

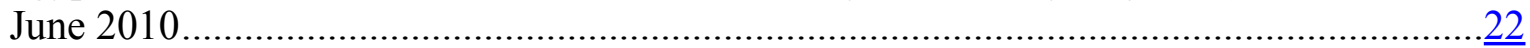

4. Some Statistics of the Distribution of Inflation Inertia in the 2000 s ................................23

5. Determinants of Inflation Inertia by Cross Country Data, 2000-2010 ..........................24

Figures

1. Expected Inflation (Consensus Forecast) and Actual Inflation (12-month, percent) ............ $\underline{5}$

2. Distribution of Inflation in the 1980s, 90s and 2000s for Countries with per Capita Income

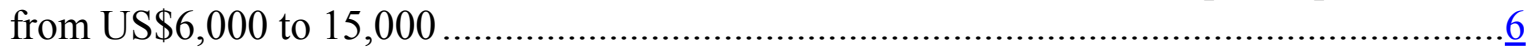

3. Density of Inflation in the 1980s, 90s and 2000s for Countries with per Capita Income from

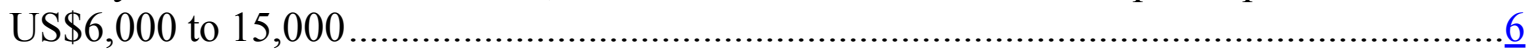

4. Inflation Distribution Conditional on the Previous Year .................................................. $\frac{9}{9}$

5. Contribution of Components with Cycles Longer than One Year..................................... 10

6. Egypt: Monthly Inflation, 2000-2010 .....................................................................

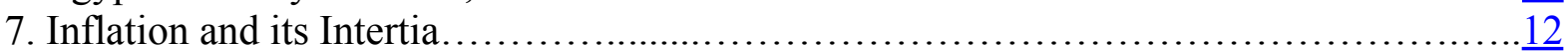


8. Impact of Shocks in the Phillips Curve and Output Gap to AR(1) Coefficient of Inflation...13

9. Impact of Shocks in the Phillips Curve and Output Gap to AR(1) Coefficient of Inflation...13

10. Midpoint of Inflation Target, 1999-2010 and Path of Midpoint of Inflation Target..........16

Appendixes

1. Coefficient of AR(1) Process of Inflation in an Example in Fuhrer (2009) .$\underline{25}$

2. Why is Inflation Inertia Overestimated when the Inflation Target Has Been Reduced during the Sample Period?

References $\underline{18}$ 


\section{INTRODUCTION}

Low inflation is a key for macroeconomic stability as evidenced by many country experiences, since high inflation in general hurt macroeconomic stability mainly through lower domestic savings by deeply negative real interest rates, lower capital accumulation due to increased uncertainty, and real appreciation of the exchange rate reflecting widened inflation differentials against trade partners. While it is important for a central bank to keep inflation low and stable, the bank must be aware of how much monetary condition tightening is required for it. Such information is critical when an economy faces strong inflationary pressures and/or is in high inflation.

Egypt that has faced double digit inflation over a couple of years and the high inflation has caused rapid real appreciation of the Egyptian pound by about 40 percent to the level before the huge devaluation in early 2003. If the Central Bank of Egypt (CBE) could reduce inflation from double digit to eliminate inflation differentials to its trade partners and other emerging market countries, it should help keep Egypt competitiveness and remove pressures on the exchange rate through giving less incentive to carry traders, since interest rate differentials should become smaller as inflation differentials decline.

If the inflation dynamics is perfectly characterized by the New Keynesian Phillips Curve (NKPC) which says that inflation in the current period is given as linear combination of the expected inflation in the next period, the output gap and (white noise) supply shocks, the answer to the above question is very simple. The central bank can achieve disinflation without any costs-i.e., without increasing unemployment rate above the natural level, or the zero sacrifice ratio-as long as its policy commitment to keep zero output gap in the future is credible for the private sector.

However, there is consensus among economists that the NKPC cannot explain persistency in inflation data (for example, Fuhrer 2009, Rudd and Whelan 2006, and Rabanal and RubioRamirez 2003). When inflation has inertia, in general, the central bank cannot achieve disinflation without elevating unemployment rate above its natural level, suggesting that the central bank faces a trade-off between disinflation and increasing unemployment. Therefore, estimating the degree of inflation inertia is a key to engineer appropriate disinflation policy for the central bank.

The main contributions of the paper are two folds. First, to empirically estimate the degree of inflation inertia in Egypt in the 2000s following a widely used method-estimating the degree of persistency defined by the sum of the coefficients in the autoregressive process of inflation by the median unbiased estimate, as in Levin et al. (2004) and Benati (2008). Second, to investigate determinants of inflation inertia using cross country data consisting of over 100 countries, where their inflation persistency is also estimated by the same method applied to Egypt.

The estimated inflation persistency suggests high inflation inertia in Egypt relative to other countries. The share of components with frequencies longer than one year in Egypt is about 40 percent. The estimated inertia is located around the upper quartile of the distribution of 
countries in the sample. The cross country Tobit regression implies that a lack of countercyclical macroeconomic policy and high fiscal deficit may cause high inflation persistency in Egypt. Therefore, more counter-cyclical monetary policy associated with establishing nominal anchor to stabilize inflation expectation and fiscal consolidation are a key for the central bank to reduce the costs of disinflation.

This paper is organized as follows. The next section provides preliminary discussions on inflation inertia: recent inflation developments in Egypt; why is inflation inertia important in the context of disinflation policy?; brief literature review of empirical studies on measuring inflation persistency; and some cross country evidence of inflation persistency based on the estimated transition matrix of inflation. The third section presents the estimated inflation inertia, defined as the median unbiased coefficient of the sum of auto regression coefficient(s), in Egypt. Section IV investigates the determinants of inflation inertia using cross country data consisting of over 100 countries. Policy implications derived from the estimated cross country regression will be discussed in Section V. Conclusions will be briefly argued in the final section.

\section{Preliminary Discussions}

\section{A. Inflation Developments in Egypt-Recent developments and Cross Country}

\section{Comparison}

Inflation (12-month) in Egypt since 2000 seems on average to have a gradually increasing trend with several elevated inflation (double digit) episodes. For example, the first spike in 2003-04 mainly reflected the passthrough effect of the huge devaluation of the Egyptian pound in $2003^{2}$. The second spike in 2006-07 was due to an avian flu outbreak and world commodity prices increase ${ }^{3}$. The third one (2008) was caused by the world commodity prices increase ${ }^{4}$. The expected inflation proxied by the inflation projections in the Consensus Forecast after 2007 has been substantially elevated compared to before that (Figure 1), implying that

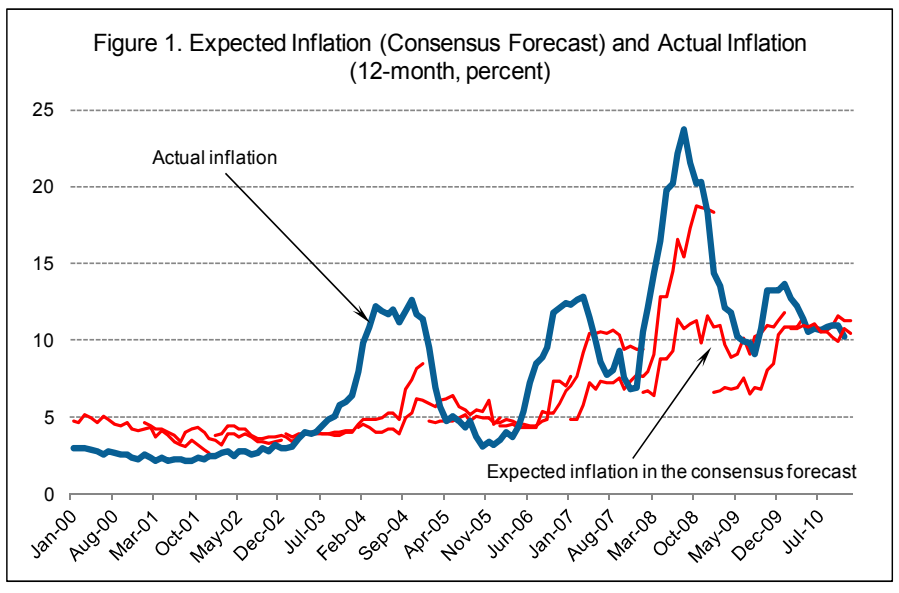
recent spikes in inflation might be feeding into higher inflation expectations, due partly to rigidities and distortions in price and wage settings, and a lack of clear nominal anchor other than exchange rate. The last factor reflects the substantial appreciation of the real exchange

\footnotetext{
${ }^{2}$ IMF (2004).

${ }^{3}$ IMF (2007).

${ }^{4}$ IMF (2008).
} 
rate of the Egyptian pound in the past couple of years beyond the end-2002 level, even surpassing the level just before the huge devaluation in January 2003.

Recent inflation in Egypt appears higher than other countries. Table 1 highlights main statistics of annual inflation (year-over-year) in countries with per capita GDP from US\$ 6,000 (equivalent to Egypt in FY2008/09) to US\$ 15,000 in the 1980s, 1990s and 2000s ${ }^{5}$. While the average inflation declined to single digit in the $2000 \mathrm{~s}$, median inflation has been within the range of 5-7 percent over the three decades, suggesting that the decline of average inflation to single digit in the 2000s simply reflects much smaller number of very high inflation episodes in the 2000s than the 1980s and 1990s. Plotting distribution of inflation in each decade confirms the view (Figure 2): the share of over 25 percent inflation in the 1980s and 1990s is about 10 percent and 15 percent, respectively, substantially higher than 2.5 percent in the 2000s. Moreover, the (smoothed) density of inflation dropping "outliers-annual inflation below -5 percent or over 25 percent" in the 1990s and the 2000s seems very similar (Figure 3 ). The mode in the 1990 s and 2000 s is about 3 percent and much closer to lower quartile than to the median and average, implying that the density of inflation is heavily skewed to the left and the simple average of the sample is not an appropriate measure to capture the location of Egypt relative to other countries. Regardless of measures, however, international comparison suggests that recent inflation in Egypt is high compared to other countries and thus achieving disinflation is very important for the central bank.
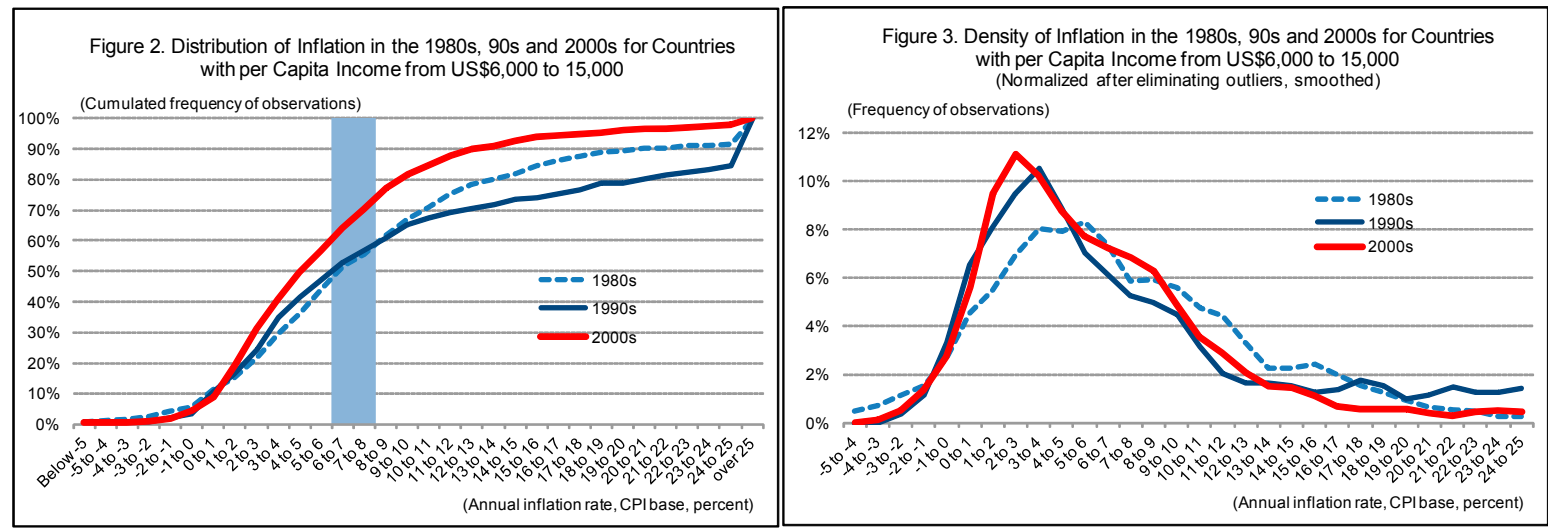

\section{B. Why Is Inflation Inertia Important for Disinflation?}

One of the most important policy implications derived from the New Keynesian Phillips Curve (NKPC) is that the central bank can achieve disinflation without elevating unemployment rate beyond the natural rate, or very low sacrifice ratio. This very strong policy implication is a direct result of the forward looking property of the NKPC:

\footnotetext{
${ }^{5}$ Egypt's per capita GDP (PPP base) reached US\$ 6,000 in FY 2008/09 (July/June) and is projected to be around US\$ 9,000 in FY 2014/15 under the current macroeconomic framework. Moreover, along this the trend, per capita GDP will surpass US\$12,000 by 2020. Comparing Egypt with countries with per capita GDP from US\$ 6,000 to US\$ 15,000 (for example, Russia: US\$ 14,900 and Argentina: US\$ 14,600) should, therefore, give insights on the location of inflation in Egypt and the inflation which Egypt should seek in the medium/long-term in the context of international comparison.
} 


$$
\pi_{t}=\beta E_{t} \pi_{t+1}+\widetilde{y}_{t}+\varepsilon_{t}=\widetilde{y}_{t}+\gamma \sum_{i=1}^{\infty} \beta^{i} E_{t} \tilde{y}_{t+i}+\varepsilon_{t}
$$

where $\tilde{y}$ is the output gap, $\varepsilon$ is error terms (assumed as white noise), interpreted as supply (non-demand) shocks, and $E$ indicates the (rational) expectation operator. Equation (1) suggests that inflation at period $t$ only depends on the current output gap and the present value of the (rationally) expected output gap in the future. If the central bank commits a policy to keep the present value of output gap is zero after period $t$ and its commitment is credible to the private sector, inflation in period $t+1$ would decline to zero regardless of the level of inflation at period $t$. Therefore, the central bank can achieve disinflation without increasing unemployment rate, or zero sacrifice ratio.

However, literature indicates that the NKPC does not appear to explain/reproduce the observed persistency of inflation (Rabanal and Rubio-Ramirez 2003). In order to overcome the drawback, it became a common practice to include a lag of inflation in the NKPC so that inflation depends on the weighted sum of its lag and the rationally expected future value (the hybrid $\mathrm{NKPC}^{6}$ ):

$$
\pi_{t}=(1-\theta) \pi_{t-1}+\theta E_{t} \pi_{t+1}+\tilde{y}_{t}+\varepsilon_{t}
$$

This modification, however, changes the policy implication (the costless disinflation) dramatically: inflation is no longer independent from its past value in the hybrid NKPC. When $\theta>0.5$, for example, the solution of the hybrid NKPC is rewritten as follows (Rudd and Whelan 2006):

$$
\pi_{t}=\frac{1-\theta}{\theta} \pi_{t-1}+\frac{\gamma}{\theta} \sum_{i=0}^{\infty} E_{t} \tilde{y}_{t+i}+\varepsilon_{t}
$$

The above solution of equation (2) implies that even when the central bank commits a policy of zero output gap in the future and the policy is credible to the private sector, inflation declines only gradually. If the central bank seeks to achieve zero inflation at period $t+1$ - this is feasible without increasing unemployment under the (pure) NKPC, the bank must commit a monetary policy to keep output below its potential for a while to reduce the inflation inherited from period $t$. The required decline in the present value of the output gap is:

$$
\sum_{i=1}^{\infty} E_{t} \widetilde{y}_{t+i}=-\frac{1-\theta}{\gamma} \pi_{t}
$$

An economy must pay costs of disinflation through the unemployment rate higher than the natural level under the hybrid NKPC, suggesting that the sacrifice ratio is positive. Therefore, it is important for central banks to empirically investigate the size of inflation inertia and its determinants. The exercise would help central banks engineer desirable disinflation.

\section{Empirical Literature on Inflation Inertia}

There are two main approaches to measure inflation inertia using macroeconomic data in the literature, as well summarized in Fuhrer (2009). The one approach estimates inflation inertia by applying the reduced-form model: usually the autoregressive regression specification is

\footnotetext{
${ }^{6}$ For the hybrid NKPC, see Gali et al. (2005).
} 
used to measure inflation inertia, where the inertia is defined as the sum of the estimated coefficients to the autoregressive items. For example, Benati (2008) estimated inflation persistency in several different countries (UK, Euro area, and US etc.) over different periods based on the medium unbiased estimation method with its confidence interval derived from the grid bootstrap method. Levin et al. (2004) used the same methodology to estimate inflation inertia of core and headline inflation in advanced countries. They found that the degree of inflation persistency appears low in inflation targeting (IT) countries, whereas it is still high in countries without IT. Interestingly, they presented that headline inflation persistency is very similar to that of core inflation in almost non IT countries. Capistran and Ramos-Francia (2006) followed the same approach and estimated inflation inertia for 10 Latin American countries from 1980 to 2006. They reported that although the estimated degree of inflation persistency seems to be very high, the degree falls once structural breaks are counted. They also mentioned that the degree of persistency appears on average declining in the region.

The other approach uses structural model(s) to estimate inflation inertia. Dossche and Everaert (2005) studied a structural time series model consisting of the hybrid New Keynesian Phillips curve, the evolution of the output gap (IS curve), and the nominal interest rate rule (Taylor rule). According to the paper, inflation persistency in the Euro area, defined by the half-life of a shock, is estimated in the rage from one quarter in case of a cost-push shock to several years for a shock to long-run inflation expectations or the output gap. Cogley and Sbordone (2006) investigated inflation inertia in modeling inflation of recognizing the slowly moving component of inflation. They found that once the model has accounted for the slow-moving variation in trend inflation, there is no need for a lag of inflation to account for the reduced form persistence of inflation. Another strategy in line with structural model is to use a Dynamic Stochastic General Equilibrium (DSGE) model to interpret structural sources of persistency derived from the observed autocorrelation of inflation (for example, Rabanal and Rubio-Ramirez 2003).

\section{Inflation persistency in Emerging Market Countries-Conditional Inflation Derived from a Transition Matrix}

Before moving to the next section estimating the inflation inertia for Egypt, it is an interesting exercise to investigate how persistent inflation is as a group in emerging market economies. This sub-section estimates the conditional probability distribution of inflation derived from the transition matrix of inflation, following Fischer et al. (2002). Inflation data (annual) of 31 emerging market countries ${ }^{7}$ defined in Filho (2010), spanning from 1980 to 2009 , is used to estimate the transition matrix of inflation, where the row and column of the matrix indicates the range of inflation in year $t$ and year $t+1$, respectively.

\footnotetext{
${ }^{7}$ Argentina, Brazil, Bulgaria, Chile, China (Mainland), Colombia, Dominican Republic, Ecuador, Egypt, El Salvador, Hungary, Indonesia, Kazakhstan, Lebanon, Malaysia, Mexico, Pakistan, Panama, Peru, Philippines, Poland, Russia, Serbia, South Africa, Sri Lanka, Tunisia, Turkey, Ukraine, Uruguay, Venezuela, and Vietnam.
} 
The estimated transition matrix of inflation in 31 emerging market countries from 1980 to 2009 suggests some inertia in inflation. In Table 2, the number in the matrix is the conditional probabilities given inflation in year $t^{8}$. For example, inflation in year $t$ in the range of 0 and 4 percent will be in the same range in year $t+1$ with about 70 percent probability, and when inflation in year $\mathrm{t}$ is between 8 and 12 percent, inflation in year $t+1$ will fall in the same range with one-third and over 70 percent in the range of 4 to 12 percent.

Inflation inertia derived from the transition matrix could be more intuitively highlighted by plotting the conditional probability density (Figure 4). The mode of each (smoothed) conditional inflation probability density in year $t+1$ is in or slightly lower than the range of the inflation in year $t$. The conditional density tends to have smaller variance as the distribution has lower inflation in year $t$, suggesting that inflation tends to be more stable and persistent as its level declines. This is another benefit of disinflation to the central banks.

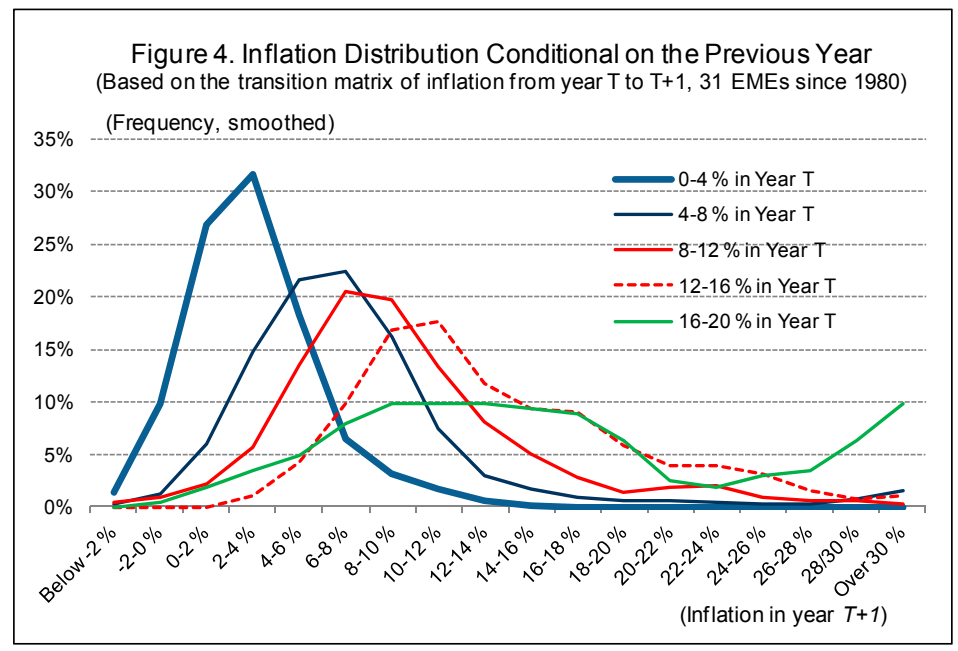

\section{INFLATION INERTIA IN EGYPT}

\section{A. Measuring Inflation Inertia by the Reduced Form Model: Re-interpretation of the Coefficient of Auto-regression Process by the Spectrum Analysis}

This section estimates inflation inertia in Egypt. While there have been several approaches to measure inflation inertia as summarized in the previous section, the paper focuses on a relatively simple measure of inflation using the reduced form model, where inflation inertia defined by the sum of coefficient(s) in $A R(p)$ process, as in Levin et al. (2004) and Benati (2008), where $p$ is the number of lags included in the model. One advantage of using the simple measure is its very light data requirement and the simplicity of the model with little room for misspecification ${ }^{9}$.

The other advantage of using the simple measure of inflation inertia derived from the univariate autoregressive process allows us to re-interpret "inertia" more intuitively in the context of the spectrum (frequency domain) analysis. Spectral analysis provides useful statistics to summarize the degree of persistency of time series data. The purpose of the

\footnotetext{
${ }^{8}$ The sum of conditional probabilities in each row is 100 percent, by its construction.

${ }^{9}$ Companion paper of this paper, "Adding Egypt to the Global Projection Model: Spillovers, Inflation Dynamics, and Implications to Monetary Policy" by Arbatli and Moriyama (2011) follows the structural model approach to investigate inflation inertia in Egypt by estimating the hybrid Phillips curve.
} 
spectrum analysis is to decompose a complex time series with cyclical components into a few underlying sinusoidal (sine and cosine) functions of particular wavelengths (or frequencies) ${ }^{10}$. Figure 5 plots the relation between the estimated autoregressive coefficient in the uni-variate monthly time series with the Augmented Dickey-Fuller (ADF) specification and the share of components containing frequencies longer than one year. Inflation becomes more persistent as the share increases and the share of long-term components appears to have non-linear relation with the estimated autoregressive coefficient(s). The speed of an increase in the share of long-run cyclical components appears accelerating as the coefficient approaches to one, and change in the value of coefficient has at most marginal impact on the share as the coefficient approaches to minus one. The non-linear property will play an important role in the cross country analysis to investigate the determinants of inflation inertia in the reduce form in

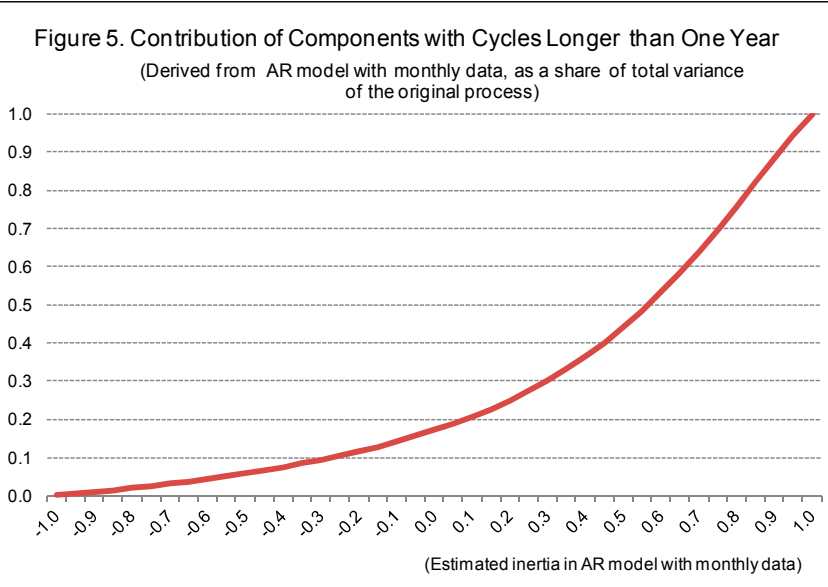
the next section.

However, inflation inertia, measured by the coefficient of the uni-variate autoregressive time series process with the ADF specification, cannot be precisely estimated by the ordinary least square (OLS) when inflation has persistency, as pointed out by Andrews (1993). In general, when a time series has some persistency, estimating the sum of the autoregressive coefficients by OLS tends to cause downward bias in the estimator. The tendency increases as inflation is more persistent. To overcome the problem, as in the literature, the paper uses the median-unbiased estimator ${ }^{11}$ following Andrews and Chen (1994) and the confidence interval constructed by Hansen's (1999) grid bootstrap, using 200 grid points and 2000 bootstrap replications at each grid point.

\section{B. Estimated Inflation Inertia in Egypt}

Monthly headline CPI inflation-the first difference of natural logarithm of seasonally adjusted CPI-taken from the IFS spanning from January 2000 to June 2010 is used to estimate the inflation inertia measured by the sum of coefficients in the autoregressive process in Egypt (Figure 6). The number of lags in the model is set to one which minimizes the Schwartz Information Criterion (SIC). Since the Chow test suggests a structural break around July 2007, the sample period is divided into two sub-periods, from January 2000 to June 2007 and from July 2007 to June 2010, and inflation inertia is estimated for each subperiod. In addition to the headline CPI inflation, inertia of the core inflation compiled by the Central Bank of Egypt (CBE) — eliminating several food items and administrative prices-is

\footnotetext{
${ }^{10}$ For a technical discussion on the spectral analysis, see Hamilton (1994).

${ }^{11}$ Code was provided by Thomas Maag (http://www.thomasmaag.net/scripts.html).
} 
estimated for comparison, although the results should be interpreted with caution due to its very short sample period (core inflation data is available only after January 2005).

Results are reported in Table 3. As expected, $A R(1)$ coefficient, a measure of inflation inertia, estimated by OLS is smaller than the median unbiased estimator, and the upper bound of the confidence interval derived from the grid bootstrap estimator is larger than that of the OLS. The estimated median unbiased inertia is about 0.5 and 0.4 in January 2001-June 2007 and July 2007-June 2010, respectively, although the two estimated coefficients are not statistically different. The estimated coefficients suggest that the share of components with frequencies longer than one year is about 0.45 and 0.35 during the two sub-periods in Egypt. Smaller inertia in the later sub-period appears reflecting more short-term shocks to inflation-mainly food prices-during the sub-period,

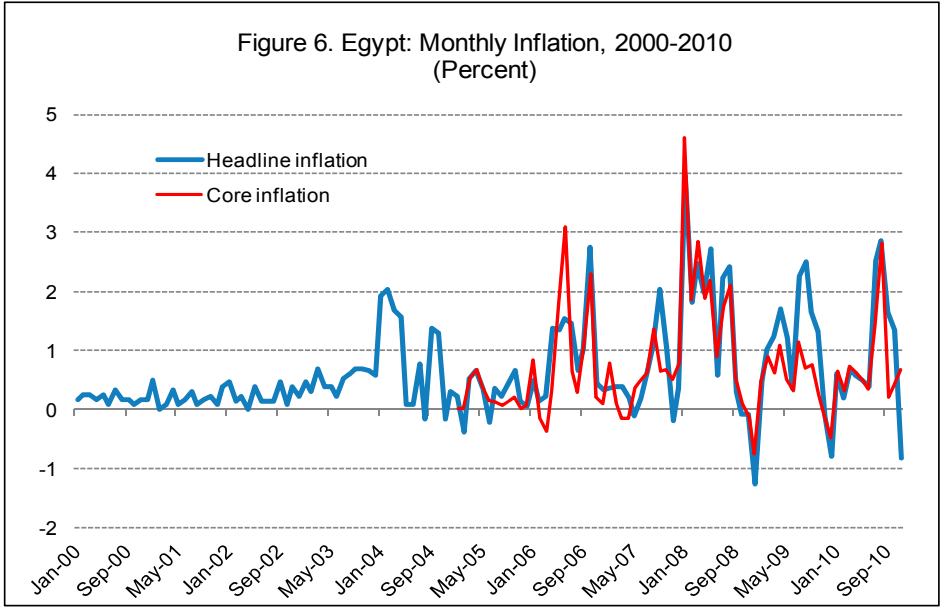
consistent with large fluctuations of month-over-month inflation after the middle of 2007 mainly due to some food items' price shocks.

Table 3 also presents the estimated inertia of the core inflation compiled by the CBE, although, as mentioned before, the results should be interpreted with caution because of its very short sample period (only after January 2005). The results are somewhat counterintuitive, although Levin et al. (2004) reported a similar result for some advanced countries without inflation targeting monetary policy framework too. While the core inflation inertia is larger than the headline inflation after the middle of 2007-this is in line with intuition since exclusion of food items from the core inflation should help increase inertia of core inflation, the inertia of the headline inflation was larger than the core inflation during the first sub-period (but the difference is not statistically significant).

\section{DETERMINANTS OF INFLATION INERTIA-Cross COUNTRY ANALYSIS}

Next questions to be addressed are (i) the size of inflation inertia in Egypt relative to other countries and (ii) determinants of inflation inertia variation across countries. This section investigates possible answers to the two questions.

\section{A. Cross Country Comparison of Inflation Inertia}

As for answer to the first question, inflation inertia of about 130 countries-covered by Global Competitiveness Report for 2009-10-is estimated using quarterly CPI inflation, defined as the first difference of natural logarithm of seasonally adjusted CPI taken from IFS or INS, spanning from Q1 2000 to Q2 2010. The number of lags is selected by the SIC and the Chow test is conducted to identify (possible) structural break(s) for each country. Table 4 
provides the summary statistics of the distribution of the estimated inertia by both the OLS and the median biased estimator. Estimated inflation inertia-measured by the sum of the coefficient(s) in the uni-variate autoregressive process-in Egypt appears well above median and average, and close to the upper quartile, suggesting that inflation in Egypt is more persistent than other countries in the sample.

Plotting the estimated inflation inertia and inflation averaged over 2000-09 indicates some positive correlation between them (Figure 7), not inconsistent with the story implied by the hybrid NKPC in Section II. In general, if monetary policy responses to inflationary pressures become less effective/timely as the cost of disinflation increases due to inflation inertia, demand/supply shocks would easily elevate inflation. On the other hand, sustained high inflation due to a lack of timely monetary policy responses and sustained positive output gap/supply shocks would be feeding into higher expected inflation, leading to higher inflation inertia. Moreover, the figure indicates

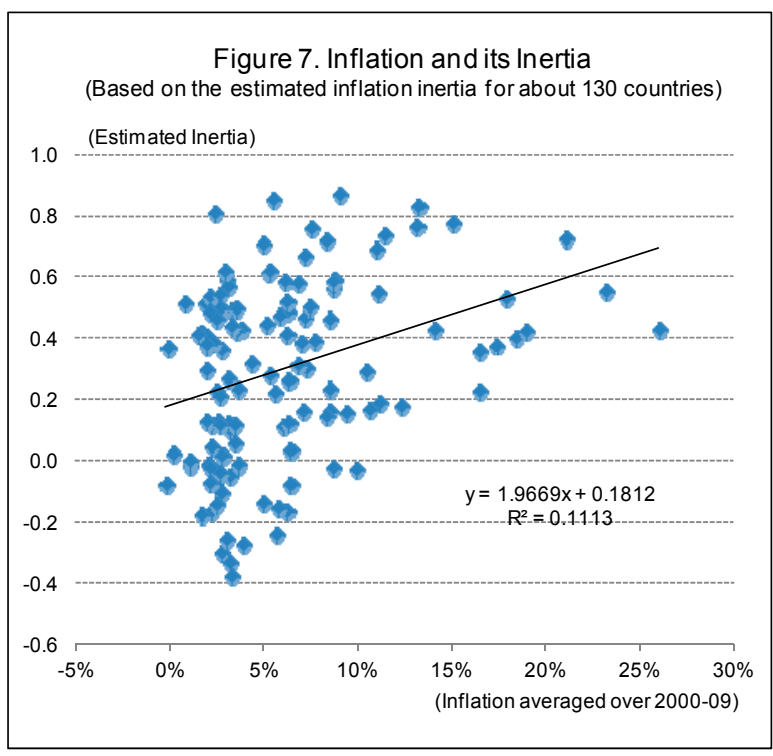
that lower inflation is likely to reduce inflation volatility and thus real interest rate, since the volatility of inflation in the ADF specification depends on the inverse of one minus the sum of the autoregressive coefficients. This is consistent with more stable inflation as inflation declines, implied by the conditional density of inflation derived from the transition matrix in Section II.

\section{B. Investigating Determinants of Inflation Inertia-Model}

Answer to the second question-determinants of inflation inertia-can be investigated by the cross country econometric analysis. Calibration based on a simple example in Fuhrer (2009) consisting of the New Keynesian Phillips Curve (NKPC) and the law of motion of the output gap characterized by $A R(1)$ process (see Appendix I) indicates the following story, as highlighted by Figures 8 and 9:

- Inflation inertia increases as price rigidities which affect the coefficient of the output gap $(\gamma)$ in the NKPC become larger (Figure 9);

- Increased volatility of a shock to inflation in the NKPC (output gap) reduces (increases) inflation inertia (Figure 8), where both of the two shocks are assumed white noise. Increased variation of the shock in the NKPC would make the output gap-characterized by $A R(1)$ process - relatively less important to determine inflation variation, leading to smaller inflation inertia. On the other hand, increased output gap shock volatility would raise the autocorrelation of inflation through bigger variation of the output gap which is $A R(1)$, making the relative size of the non- 
persistent shock in the NKPC smaller (see Appendix I) and thus bigger autocorrelation of inflation; and

- Increased persistency in output gap would increase inflation inertia, since the output gap affects inflation in the NKPC.

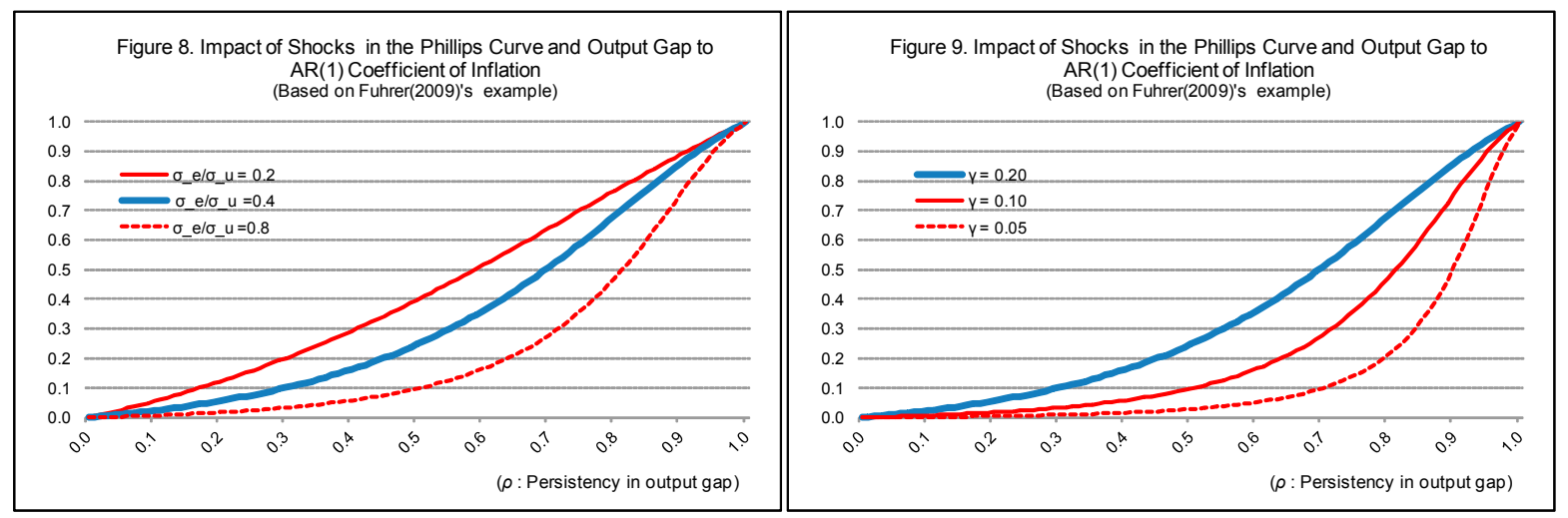

Next step is to choose appropriate proxies for factors causing variation of inflation persistency across countries, consistent with the observations derived from the above calibration.

- The degree of market rigidities is proxied by market efficiency index in the Global Competitiveness Report. Increased rigidities in goods and labor market would increase persistency in inflation through increasing the coefficient of output gap in the NKPC and the output gap persistency (Gali 2008);

- Volatility of non-interest government expenditure over GDP: This is a proxy for the volatility of a shock to output gap through the demand side. The output gap has more fluctuation as the volatility increases, leading to higher persistency in inflation (as in Figure 9);

- Volatility of terms of trade change: This is a proxy for a (supply) shock to inflation in the NKPC: While increased volatility in principle reduces inflation persistency (Figure 9), terms of trade may affect inflation inertia through the output gap as well as supply shocks in the NKPC in commodity exporters, implying that the sign is qualitatively inconclusive in the economic theory;

- Rep capita GDP (PPP base): The share of food and energy in CPI-high volatility items in the CPI basket-tends to decline as per capita income level rises. Per capita GDP (PPP), therefore, can be a good proxy to control the variation of supply shocks, especially food items, in the NKPC;

- Fiscal dominance: When monetary policy cannot timely respond to inflation, monetary policy becomes pro-cyclical and thus could make inflation more persistent. As mentioned by Fraga et al. (2003), fiscal dominance is a big challenge for timely implementation of monetary policy to contain inflationary pressures. The paper uses 
fiscal deficit as a share of GDP averaged over the sample period is used as a proxy of fiscal dominance;

- Monetary policy framework: Monetary policy more focusing on stabilizing inflation could reduce inflation persistency through smaller persistency in the output gap and anchoring inflation expectations, as in the literature. Inflation targeting and advanced economy dummies will be inserted as proxies for monetary policy framework which appear help reduce inflation persistency; and

- Measurement errors in CPI: Measurement errors in CPI create negatively correlated measurement errors in inflation, generating downward bias in the estimated coefficient(s) in the uni-variate autoregressive process. Good institutions and income level can be good proxies to control cross country variation of the measurement errors in inflation.

\section{The Data and Methodology}

Macroeconomic data (terms of trade, fiscal variables, per capita GDP) is taken from the IMF's World Economic Outlook (WEO) database, averaged over 2000 to 2009, where per capita GDP is averaged over 1995-99 in order to avoid endogeneity Volatilities are derived from 2000-09 data. Market rigidities are proxied by the goods market efficiency score averaged over 2007-2009 in the Global Competitiveness Report, where the labor market efficiency score in the report is not included in the paper, counting its strong correlation to the goods market efficiency score. Classification of country groups follows that in the Spring 2010 WEO. Inflation targeting dummy - taking one when a country adopted inflation targeting monetary policy framework in 2001-is based on the oldest available data in the Annual Report on Exchange Rate Arrangement and Exchange Restrictions by the IMF, in order to avoid endogeneity caused by a change in monetary policy framework during the sample period.

Simply applying the Ordinary Least Square (OLS) to the model may cause bias in the estimator because the OLS cannot incorporate the non-linear relation between the estimated coefficient(s) of the autoregressive and the share of the components of inflation with longer frequencies derived from the spectrum analysis, as presented in Figure 6. In addition to OLS, therefore, the Tobit model is used to estimate the model to avoid the bias. The model is estimated not only for all samples but also for smaller sub-samples: advanced countries and commodity exporting countries, since several variables included in the right hand side of the model appear to have different signs across different groups. For example, measurement errors in inflation in advanced countries should be substantially smaller than those in developing countries. Fiscal deficit in advanced countries may not affect inflation expectation as in developing countries because their deep financial markets help avoid fiscal dominance, compared to emerging market and low income countries. Terms of trade in commodity exporters should affect inflation persistency through demand shocks to the output gap too-in line with the expenditure effect of Dutch disease in the literature-rather than supply shocks to inflation in the NKPC. 


\section{Results}

Table 5 presents the results. Main findings are summarized as follows:

- Counting the non-linearity does help increase explanatory power of the model, as indicated by higher adjusted $R^{2}$ by the Tobit model;

- The volatility of non-interest fiscal expenditure as a share of GDP - a proxy for the volatility of demand shock to the output gap-significantly affects inflation inertia, suggesting that increased demand shock volatility could increase inflation inertia. The insignificant effect of the volatility in the advanced countries, on the other hand, appears reflecting that well-anchored inflation expectations supported by countercyclical macroeconomic policies has alleviated the impact of demand shocks volatility to inflation inertia in the advanced countries;

- While fiscal deficit does affect inflation inertia for all sample countries, advanced economies appear insulated from it. This observation is not inconsistent with the intuition that deep financial markets enough to absorb government financing requirements and well-anchored inflation expectation have helped mitigate the impact of fiscal dominance to inflation inertia in advanced countries;

- Advanced countries dummy is significantly negative, implying that well anchored inflation expectations in advanced countries due to prudent macroeconomic policies have helped reduce inflation persistency. This is in line with the discussion of "great moderation";

- While goods market inefficiency does not matter for the whole sample, it does have statistically significant effect on inflation inertia in advanced countries. This observation may reflect that supply shocks in the NKPC play a substantially larger role to determine inflation than the output gap in developing countries than advanced economies; and

- Inflation targeting monetary policy framework in developing countries does not appear helping reduce inflation persistency. This counter-intuitive result may partly be due to the upward bias of the estimated coefficient(s) in the autoregressive process when the inflation target has been reduced during the sample period (see Appendix II for technical description), which is common among the emerging market countries adopting inflation targeting monetary policy framework in the 2000s (Figures 10). To control the bias, inserting a dummy which has value one for countries that have reduced the inflation target level during the sample period made the estimated coefficient for the dummy of inflation targeting in developing countries much smaller and less significant. 

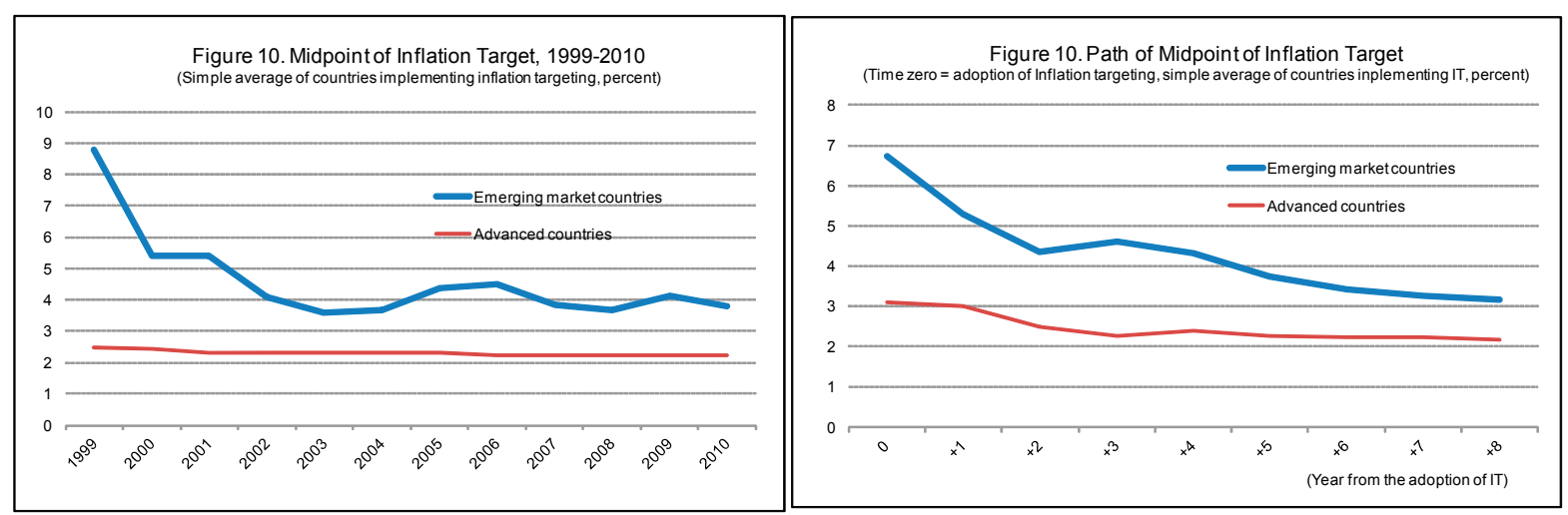

\section{Policy Implications}

The results presented in Section IV have two important policy implications to reduce inflation inertia, important information to engineer monetary policy to achieve disinflation which is considered as a precondition for the full-fledged inflation targeting monetary policy framework and maintaining competitiveness in Egypt against its trade partners.

The first is the importance of counter-cyclical macroeconomic policies to reduce inflation inertia. This is implied by the significantly positive effect of the volatility of demand shocks proxied by primary fiscal expenditure as a share of GDP in the Tobit regression. Pro-cyclical macroeconomic policy due especially to a lack of timely response to demand shocks would propagate the shocks to the output gap, leading to bigger fluctuations of the output gap and higher inflation persistency through the Phillips curve. In an extreme case, for example, that macroeconomic policy immediately responds and perfectly offsets demand shocks, inflation depends only on white noise supply shocks in the NKPC since the output gap stays at zero for all periods, leading zero inflation inertia.

The second implication is the additional benefit of fiscal consolidation to disinflation, since fiscal consolidation would help reduce inflation through lower inertia in addition to smaller aggregate demand. Historically, persistent large fiscal deficit (or fiscal dominance) appears causing monetization and/or irresponsive nominal interest rate to inflationary pressures to avoid additional interest burden in the fiscal accounts, making monetary policy more procyclical and thus inflation more persistent.

In sum, reducing fiscal deficit and more timely response of macroeconomic policy to off-set demand pressures are a key to reduce inflation inertia and thus the cost of disinflation ${ }^{12}$. It is worth mentioning that inflation "inertia" reflects inertia in inflation expectations. The fiscal deficit and volatility of primary fiscal expenditure (as a share of GDP) were used as proxies for pro-cyclicality (and inflexibility of interest rate) of macroeconomic policies, because intuition suggests that inflation should have bigger momentum as macroeconomic policy becomes more pro-cyclical, leading to higher inertia. If the private sector (household and

\footnotetext{
${ }^{12}$ Interestingly, the two features are also generally considered as preconditions for the adoption of full-fledged inflation targeting monetary policy framework.
} 
firms) believe high pro-cyclicality of macroeconomic policies in the future, therefore, such expectation should increase inertia in inflation expectations and thus inflation inertia now.

However, the estimated inflation inertia in the paper does not have information enough to identify the required change in the (present value of the) output gap to remove inflation differentials between Egypt and its trade partners to keep Egypt's competitiveness. This is implied by the fact that while the estimated coefficient for a lag of inflation in the hybrid NKPC (equation (2)) is critical to estimate the sacrifice ratio for disinflation, the estimated inflation inertia by the reduced form model in the paper can include inflation persistency due to the persistency in the output gap (and the real exchange rate and the foreign output gap in a small open economy model) too. This is the direct result of the estimate based on the reduced form model. Estimating the parameters in the hybrid NKPC is, therefore, necessary to obtain the sacrifice ratio to achieve disinflation in Egypt ${ }^{13}$.

\section{Conclusions}

This paper estimated inflation inertia in Egypt and investigated the determinants of the inertia using cross country data consisting of about 130 countries. First, the paper estimated inflation inertia in Egypt following a commonly used methodology in Benati (2008) and found that the share of components with frequencies longer than one year in Egypt is about 40 percent.

Second, inflation inertia of about 130 countries was estimated following the same methodology used for Egypt. Estimated density of the inflation inertia suggests that inflation inertia in Egypt is relatively high compared to other countries, located around the upper quartile in the sample. The cross country regression implies that a lack of counter-cyclical macroeconomic policy and high fiscal deficit may cause high persistency in Egypt.

Therefore, more counter-cyclical monetary policy associated with establishing nominal anchor to stabilize inflation expectation is a key to reduce costs of disinflation, in addition to keep the committed the fiscal consolidation to reduce deficit by 5 percentage points by FY 2014/15.

However, estimating the parameters in the hybrid NKPC is necessary to figure out how much the output gap needs to decline to achieve disinflation, necessary information for the central bank to engineer monetary policy during the transition periods until inflation reaches to trade partners' level. This is a promising and interesting research topic in the future.

\footnotetext{
${ }^{13}$ See Arbatli and Moriyama (2011) on the hybrid NKPC in Egypt, estimated by applying the Global Projection Model.
} 


\section{References}

Andrews, Donald W. K. (1993): "Exactly Median-Unbiased Estimation of First Order Autoregressive/Unit Root Models," Econometrica, 61 (1), 139-165.

Andrews, Donald W. K. and Hong-Yuan Chen (1994): “Approximately Median-Unbiased Estimation of Autoregressive Models," Journal of Business \& Economic Statistics, 12 (2), 187-204.

Arbatli, Elif and Kenji Moriyama (2011): "Adding Egypt to the Global Projection Model:

Spillovers, Inflation Dynamics, and Implications to Monetary Policy," IMF Working Paper 11/108.

Benati, Luca (2008): "Investigating Inflation Persistence across Monetary Regimes," Quarterly Journal of Economics, August 2008, 1005-1060.

Cogley, Timothy and Argia M. Sbordone (2006): “Trend Inflation and Inflation persistency in the New Keynesian Phillips Curve", Federal Reserve Bank of New York Staff Report No. 270.

Capistran, Carlos and Manuel Ramos-Francia (2006): "Inflation Dynamics in latin America", Bank de Mexico Working Paper No. 2006-11.

Dossche, Maarten and Gerdie Everaert (2005): Measuring Inflation Persistence: A Structural Time Series Approach, ECB Working Paper No. 495.

Filho, Irineu de Carvalho (2010): "Inflation Targeting and the Crisis: A Empirical Assessment”, IMF Working Paper 10/45.

Fischer, Stanley, Ratna Sahay, and Carlos A. Vegh (2002): "Hyper- and High Inflation", Journal of Economic Literature, 40 (3), 838-880.

Fraga, Arminio, Ilan Goldfajn, and Andre Minella (2003): "Inflation Targeting in Emerging Market Economies," NBER Macroeconomics Annual, Vol. 18, 365-400.

Fuhrer, Jeffrey C. (2009): “Inflation Persistence,” Federal Reserve Bank of Boston Working Papers No. 09-14.

Gali, Jordi (2008): Monetary Policy, Inflation, and the Business Cycle, Princeton University Press, Princeton, NJ.

Gali, Jordi, Mark Gertler, and J. David Lopez-Salido (2005): "Robustness of the Estimates of the Hybrid New Keynesian Phillips Curve," Journal of Monetary Economics, 52, 1107-1118.

Hamilton, James D. (1994): Time Series Analysis, Princeton University Press, Princeton, NJ. 
Hansen, Bruce E. (1999): “The Grid Bootstrap and the Autoregressive Model," Review of Economics and Statistics, 81 (4), 594-607.

International Monetary Fund (2004): Arab Republic of Egypt, 2004 Article IV Consultation Staff Report, Washington, D.C.

International Monetary Fund (2007): Arab Republic of Egypt, 2007 Article IV Consultation Staff Report, Washington, D.C.

International Monetary Fund (2008): Arab Republic of Egypt, 2008 Article IV Consultation Staff Report, Washington, D.C.

Levin, Andrew T., Fabio M. Natalucci, and Jeremy M. Piger (2004): "The Macroeconomic Effects of Inflation Targeting," Federal Reserve Bank of St. Louis Review, July/August 2004, 86 (4), 51-80.

Levin, Andrew T., Fabio M. Natalucci, and Jeremy M. Piger (2004): "Explicit Inflation Objectives and Macroeconomic Outcomes," European Central Bank Working Paper No. 383.

Rabanal, Pau and Juan F. Rubio-Ramirez (2003): "Inflation Persistence: How Much Can We Explain?” Federal Reserve Bank of Atlanta Economic Review, Second Quarter 2003, 43-55.

Rudd, Jeremy and Karl Whelan (2006): "Can Rational Expectations Sticky-Price Models Explain Inflation Dynamics," American Economic Review, 96 (1), 303-320.

World Economic Forum (2008, 2009, 2010): The Global Competitiveness Report, 2007-08, 2008-09, 2009-10. 
Table 1. Statistics of the Distribution of Inflation for Countries with per capita GDP (PPP base) from US $\$ 6,000$ to 15,000

(Annual CPI inflation, percent)

\begin{tabular}{lrrr}
\hline & $1980 \mathrm{~s}$ & $1990 \mathrm{~s}$ & $2000 \mathrm{~s}$ \\
\hline Average & 12.3 & 16.4 & 6.6 \\
Median & 6.6 & 6.4 & 5.1 \\
Standard deviation & 21.5 & 33.6 & 6.9 \\
Lower quartile & 3.5 & 3.1 & 2.3 \\
Upper quartile & 11.8 & 16.8 & 8.6 \\
Mode in the smoothed histogram 1/ & 5.5 & 3.5 & 2.5 \\
Number of observations & 305 & 305 & 460 \\
$\quad$ of which, outliers & 28 & 49 & 11 \\
\hline
\end{tabular}

1/ Eliminating outliers, where outliers are annual inflation either below -5 percent or above 25 percent. 
Table 2. Emerging Market Countries: Transition Matrix, 1980-2009

$$
\text { (Percent) }
$$

\begin{tabular}{|c|c|c|c|c|c|c|c|c|}
\hline \multirow{2}{*}{$\begin{array}{c}\text { Range of inflation } \\
\text { in yeart }\end{array}$} & \multicolumn{7}{|c|}{ Year $t+1$} & \multirow{2}{*}{$\begin{array}{c}\text { Number of } \\
\text { observations }\end{array}$} \\
\hline & Below $0 \%$ & $0-4 \%$ & $4-8 \%$ & $8-12 \%$ & $12-16 \%$ & $16-20 \%$ & Over $20 \%$ & \\
\hline Below $0 \%$ & 37.5 & 37.5 & 18.8 & 0.0 & 0.0 & 0.0 & 6.3 & 16 \\
\hline $0-4 \%$ & 4.1 & 72.3 & 18.2 & 4.7 & 0.7 & 0.0 & 0.0 & 148 \\
\hline $4-8 \%$ & 1.2 & 19.8 & 47.1 & 22.1 & 4.7 & 1.2 & 4.1 & 172 \\
\hline $8-12 \%$ & 0.7 & 5.9 & 37.0 & 33.3 & 12.6 & 3.7 & 6.7 & 135 \\
\hline $12-16 \%$ & 0.0 & 0.0 & 12.5 & 40.6 & 17.2 & 15.6 & 14.1 & 64 \\
\hline $16-20 \%$ & 0.0 & 5.9 & 11.8 & 19.6 & 19.6 & 17.6 & 25.5 & 51 \\
\hline Over $20 \%$ & 0.4 & 0.8 & 2.3 & 2.7 & 5.7 & 8.4 & 79.7 & 261 \\
\hline Total & & & & & & & & 847 \\
\hline
\end{tabular}


Table 3. Egypt: Estimated Headline CPI Inflation (Monthly, Seasonally Adjusted) Inertia, 2000-June 2010

\begin{tabular}{|c|c|c|c|c|c|c|c|c|c|c|c|}
\hline & \multirow{3}{*}{$\begin{array}{c}\text { AR } \\
1 /\end{array}$} & \multicolumn{2}{|c|}{ Estimated Inertia } & \multicolumn{4}{|c|}{ Confidence Interval of Inertia ( 90 percent) } & \multicolumn{4}{|c|}{ Statistics derived from OLS } \\
\hline & & \multirow[t]{2}{*}{ OLS } & \multirow{2}{*}{$\begin{array}{c}\text { Median } \\
\text { unbiased }\end{array}$} & \multicolumn{2}{|c|}{ OLS } & \multicolumn{2}{|c|}{ Grid Bootstrap } & \multirow[b]{2}{*}{$A I C$} & \multirow[b]{2}{*}{$S I C$} & \multirow[b]{2}{*}{ D. $W$. } & \multirow[b]{2}{*}{$A d j-R^{2}$} \\
\hline & & & & Lower & Upper & Lower & Upper & & & & \\
\hline January 2000-July 2007 & 1 & 0.469 & 0.510 & 0.312 & 0.625 & 0.350 & 0.673 & -8.103 & -8.021 & 2.122 & 0.290 \\
\hline August 2007-June 2010 & 1 & 0.333 & 0.424 & 0.070 & 0.596 & 0.147 & 0.741 & -6.815 & -6.681 & 1.998 & 0.192 \\
\hline \multicolumn{12}{|c|}{ Core vs Headline CPI inflation since January 2005} \\
\hline \multicolumn{12}{|l|}{ Headline inflation } \\
\hline January 2005-November 2007 & 1 & 0.485 & 0.606 & 0.227 & 0.744 & 0.318 & 1.075 & -7.620 & -7.485 & 1.902 & 0.248 \\
\hline December 2007-June 2010 & 1 & 0.227 & 0.330 & -0.067 & 0.521 & 0.016 & 0.671 & -6.736 & -6.597 & 1.993 & 0.227 \\
\hline \multicolumn{12}{|l|}{ Core inflation } \\
\hline January 2005-September 200; & 1 & 0.357 & 0.461 & 0.078 & 0.637 & 0.169 & 0.869 & -7.051 & -6.914 & 1.670 & 0.087 \\
\hline October 2007-June 2010 & 1 & 0.326 & 0.421 & 0.052 & 0.599 & 0.129 & 0.746 & -7.163 & -7.027 & 2.266 & 0.401 \\
\hline
\end{tabular}

1/ Based on SIC for the whole sample periods. 
Table 4. Some Statistics of the Distribution of Inflation Inertia in the 2000s

\begin{tabular}{lcc}
\hline & OLS & Median Unbiased \\
\hline Egypt & 0.36 & 0.48 \\
Cross country estimate & & \\
Average & 0.19 & 0.30 \\
Median & 0.20 & 0.36 \\
Standard deviation 1/ & 0.26 & 0.29 \\
Lower quartile & -0.03 & 0.06 \\
Upper quartile & 0.37 & 0.51 \\
Mode in the smoothed histogram & 0.35 & 0.45 \\
Number of samples & 131 & 127 \\
\hline
\end{tabular}

1/ Grid bootstrap method for median unbiased estiomator. 
Table 5. Determinants of Inflation Inertia by Cross Country Data, 2000-2010 1/

\begin{tabular}{|c|c|c|c|c|c|c|c|c|c|}
\hline \multirow{4}{*}{$\begin{array}{c}\text { Sample group } \\
\text { Dependent variable } \\
\text { Methodology } \\
\text { Left censoring point }\end{array}$} & \multicolumn{4}{|c|}{ All countries } & \multicolumn{3}{|c|}{ Advanced countries } & \multicolumn{2}{|c|}{ Commodity exporters } \\
\hline & \multirow{3}{*}{$\begin{array}{c}\text { Inertia } \\
\text { OLS }\end{array}$} & \multirow{3}{*}{$\begin{array}{l}\text { Inertia } \\
\text { Tobit } \\
0 \\
\end{array}$} & \multirow{3}{*}{$\begin{array}{c}\text { Inertia } \\
\text { Tobit } \\
0 \\
\end{array}$} & \multirow{3}{*}{$\begin{array}{c}\text { Inertia } \\
\text { (significantly } \\
\text { positive) } \\
\text { Tobit } \\
0 \\
\end{array}$} & \multirow{3}{*}{$\begin{array}{c}\text { Inertia } \\
\text { OLS }\end{array}$} & \multirow{3}{*}{$\begin{array}{l}\text { Inertia } \\
\text { Tobit } \\
0 \\
\end{array}$} & \multirow{3}{*}{$\begin{array}{l}\text { Inertia } \\
\text { Tobit } \\
0 \\
\end{array}$} & \multirow{3}{*}{$\begin{array}{c}\text { Inertia } \\
\text { OLS }\end{array}$} & \multirow{3}{*}{$\begin{array}{c}\text { Inertia } \\
\text { (significantly } \\
\text { positive) } \\
\text { Tobit } \\
0\end{array}$} \\
\hline & & & & & & & & & \\
\hline & & & & & & & & & \\
\hline $\begin{array}{c}\text { Goods market efficiency } \\
\text { (from Global Competitiveness Report) }\end{array}$ & $\begin{array}{l}0.056 \\
(0.77)\end{array}$ & $\begin{array}{l}0.064 \\
(0.86)\end{array}$ & $\begin{array}{l}0.065 \\
(0.87)\end{array}$ & $\begin{array}{l}0.127 \\
(0.87)\end{array}$ & $\begin{array}{l}0.309 \\
(1.35)\end{array}$ & $\begin{array}{c}0.437 \\
(1.81)^{*}\end{array}$ & $\begin{array}{c}0.418 \\
(1.78)^{*}\end{array}$ & $\begin{array}{l}-0.065 \\
(-0.50)\end{array}$ & $\begin{array}{l}-0.133 \\
(-0.53)\end{array}$ \\
\hline $\begin{array}{l}\text { Volatility of non-interest fiscal expenditure } \\
\qquad \text { (as a share of } G D P)\end{array}$ & $\begin{array}{c}6.089 \\
(3.09)^{* * * *}\end{array}$ & $\begin{array}{c}6.270 \\
(3.15)^{* * *}\end{array}$ & $\begin{array}{c}6.253 \\
(3.15)^{* * *}\end{array}$ & $\begin{array}{c}10.147 \\
(2.51)^{* *}\end{array}$ & $\begin{array}{l}12.881 \\
(1.83)^{*}\end{array}$ & $\begin{array}{c}11.825 \\
(1.70)\end{array}$ & $\begin{array}{r}9.348 \\
(1.31)\end{array}$ & $\begin{array}{l}5.431 \\
(1.69)\end{array}$ & $\begin{array}{l}10.463 \\
(1.59)\end{array}$ \\
\hline Fiscal deficit as a share of GDP & $\begin{array}{c}1.204 \\
(1.77)^{*}\end{array}$ & $\begin{array}{c}1.373 \\
(1.98)^{* *}\end{array}$ & $\begin{array}{c}1.225 \\
(1.74)^{*}\end{array}$ & $\begin{array}{l}2.116 \\
(1.48)\end{array}$ & $\begin{array}{r}1.044 \\
(0.56)\end{array}$ & $\begin{array}{r}0.421 \\
(0.21)\end{array}$ & $\begin{array}{l}-0.252 \\
(-0.12)\end{array}$ & $\begin{array}{c}2.249 \\
(2.04)^{*}\end{array}$ & $\begin{array}{c}6.571 \\
(2.35)^{* *}\end{array}$ \\
\hline Volatility of Terms of Trade change & $\begin{array}{l}-0.189 \\
(-0.38)\end{array}$ & $\begin{array}{l}-0.191 \\
(-0.38)\end{array}$ & $\begin{array}{l}-0.169 \\
(-0.34)\end{array}$ & $\begin{array}{l}-1.050 \\
(-0.99)\end{array}$ & $\begin{array}{l}-3.727 \\
(-1.06)\end{array}$ & $\begin{array}{c}-7.113 \\
(-1.80)^{*}\end{array}$ & $\begin{array}{l}-6.853 \\
(-1.79)\end{array}$ & $\begin{array}{l}0.441 \\
(0.53)\end{array}$ & $\begin{array}{l}1.484 \\
(0.93)\end{array}$ \\
\hline Advanced countries dummy & $\begin{array}{c}-0.220 \\
(-2.18)^{* *}\end{array}$ & $\begin{array}{c}-0.248 \\
(-2.39)^{* *}\end{array}$ & $\begin{array}{c}-0.223 \\
(-2.11)^{* *}\end{array}$ & $\begin{array}{c}-0.441 \\
(-2.14)^{* *}\end{array}$ & & & & & \\
\hline \multicolumn{10}{|l|}{ Inflation Targeting dummies (as of 2001) } \\
\hline Advanced countries & $\begin{array}{l}0.043 \\
(0.40)\end{array}$ & $\begin{array}{l}0.061 \\
(0.54)\end{array}$ & $\begin{array}{l}0.034 \\
(0.30)\end{array}$ & $\begin{array}{l}0.021 \\
(0.09)\end{array}$ & $\begin{array}{l}0.143 \\
(1.04)\end{array}$ & $\begin{array}{l}0.216 \\
(1.55)\end{array}$ & $\begin{array}{l}0.132 \\
(0.85)\end{array}$ & & \\
\hline Non-advanced countries & $=\begin{array}{l}0.117 \\
(0.96)\end{array}$ & $\begin{array}{r}0.118 \\
(0.97)\end{array}$ & $\begin{array}{l}0.064 \\
(0.48)\end{array}$ & $\begin{array}{l}0.215 \\
(0.94)\end{array}$ & & & & $\begin{array}{r}0.050 \\
\quad(0.17)\end{array}$ & $\begin{array}{l}0.204 \\
(0.40)\end{array}$ \\
\hline $\ln (G D P)_{-1}$ & $\begin{array}{c}0.086 \\
(2.50)^{* *}\end{array}$ & $\begin{array}{c}0.094 \\
(2.68)^{* *}\end{array}$ & $\begin{array}{c}0.087 \\
(2.45)^{* *}\end{array}$ & $\begin{array}{c}0.189 \\
(2.71)^{* *}\end{array}$ & $\begin{array}{l}0.411 \\
(1.22)\end{array}$ & $\begin{array}{l}0.469 \\
(1.39)\end{array}$ & $\begin{array}{l}0.473 \\
(1.44)\end{array}$ & $\begin{array}{l}0.092 \\
(1.65)\end{array}$ & $\begin{array}{c}0.339 \\
(2.70)^{* *}\end{array}$ \\
\hline Constant & $\begin{array}{l}-0.286 \\
(-0.77)\end{array}$ & $\begin{array}{l}-0.325 \\
(-0.85)\end{array}$ & & $\begin{array}{l}-1.101 \\
(-1.43)\end{array}$ & $\begin{array}{l}-2.523 \\
(-0.95)\end{array}$ & $\begin{array}{l}-2.396 \\
(-0.91)\end{array}$ & & $\begin{array}{l}-0.837 \\
(-1.31)\end{array}$ & $\begin{array}{c}-3.639 \\
(-2.54)^{* *}\end{array}$ \\
\hline $\begin{array}{l}\text { Reducing targeted inflation } \\
\quad \text { (more than one percentage point) }\end{array}$ & & & $\begin{array}{r}0.104 \\
(1.05)\end{array}$ & & & & $\begin{array}{l}0.263 \\
(1.06)\end{array}$ & & \\
\hline Number of samples & 120 & 120 & 120 & 120 & 30 & 30 & 30 & 28 & 28 \\
\hline Censored observations & & 25 & 25 & 64 & & 10 & 10 & & 15 \\
\hline Mean squared error ( $\sigma$ for Tobit) & 0.278 & 0.277 & 0.276 & 0.502 & 0.286 & 0.275 & 0.267 & 0.255 & 0.439 \\
\hline Adjusted $R^{2}$ (Pseudo $R^{2}$ for Tobit) & 0.112 & 0.237 & 0.248 & 0.103 & -0.012 & 0.273 & 0.310 & 0.036 & 0.263 \\
\hline
\end{tabular}

$1 /$ Numbers in parenthesis are t-statistics. $* * *, * *$ and $*$ indicate significant (both tales) at 1percent, 5 percent, and 10 percent, respectively. 


\section{Appendix I. Coefficient of $A R(1)$ Process of Inflation in an Example in Fuhrer (2009)}

A simple example to illustrate the effects of structural parameters to inflation persistency presented in Fuhrer (2009) consists of the following three equations.

$$
\begin{aligned}
& \pi_{t}=\beta E_{t} \pi_{t+1}+\widetilde{y}_{t}+\varepsilon_{t}, \\
& \tilde{y}_{t}=\rho \widetilde{y}_{t-1}+u_{t}, \\
& \operatorname{Var}\left(\varepsilon_{t}, u_{t}\right)=\left[\begin{array}{cc}
\sigma_{\varepsilon}^{2} & 0 \\
0 & \sigma_{u}^{2}
\end{array}\right] .
\end{aligned}
$$

Solving the above system yields

$$
\pi_{t}=\frac{\gamma}{1-\beta \rho} \tilde{y}_{t}+\varepsilon_{t}=\frac{\gamma \rho}{1-\beta \rho} \tilde{y}_{t-1}+\frac{\gamma}{1-\beta \rho} u_{t}+\varepsilon_{t}, \text { and } \operatorname{Var}\left(\pi_{t}\right)=\frac{\gamma^{2}}{(1-\beta \rho)^{2}} \frac{\sigma_{u}^{2}}{1-\rho^{2}}+\sigma_{\varepsilon}^{2} .
$$

Suppose that inflation is estimated in $A R(1)$ uni-variate process: $\pi_{t}=\alpha+\varphi \pi_{t-1}+e_{t}$.

Probability limit of coefficient of a lag of inflation is given by the following formula.

$$
p \lim \hat{\varphi}=\frac{\operatorname{Cov}\left(\pi_{t}, \pi_{t-1}\right)}{\operatorname{Var}\left(\pi_{t-1}\right)}=\frac{\gamma^{2} \rho \sigma_{u}^{2}}{\gamma^{2} \sigma_{u}^{2}+\sigma_{\varepsilon}^{2}(1-\beta \rho)^{2}\left(1-\rho^{2}\right)}=\frac{\gamma^{2} \rho}{\gamma^{2}+(1-\beta \rho)^{2}\left(1-\rho^{2}\right) \frac{\sigma_{\varepsilon}^{2}}{\sigma_{u}^{2}}}
$$

The right hand side of the above equation suggests that inflation inertia, measured by the coefficient in the uni-variate autoregressive process, has positive correlation to $(\gamma, \rho)$ and negative correlation to the ratio of the variance of the shock to inflation to that output gap (i.e., $\sigma_{\varepsilon}^{2} / \sigma_{u}^{2}$ ). 


\section{Appendix II: Why is Inflation Inertia Overestimated when the Inflation Target Has Been Reduced during the Sample Period?}

Suppose the behavior of inflation with the true model, counting a change in the targeted inflation rate, is described as follows.

$$
\begin{aligned}
& \pi_{t}-\bar{\pi}=\alpha\left(\pi_{t-1}-\bar{\pi}\right)+\varepsilon_{t} \text { when } t \leq T, \text { and } \\
& \pi_{t}-\pi^{*}=\alpha\left(\pi_{t-1}-\pi^{*}\right)+\varepsilon_{t} \text { after } T,
\end{aligned}
$$

where $\bar{\pi}$ and $\pi^{*}$ are the inflation targeted by the central bank before and after period $T$, respectively, and $\alpha<1$. Applying OLS gives:

$$
-\hat{\alpha}=\frac{\sum_{i=1}^{T}\left(\pi_{t}-\bar{\pi}\right)\left(\pi_{t-1}-\bar{\pi}\right)}{\sum_{i=1}^{N}\left(\pi_{t}-\bar{\pi}\right)^{2}}=\frac{\sum_{i=T+1}^{N}\left(\pi_{t}-\pi^{*}\right)\left(\pi_{t-1}-\pi^{*}\right)}{\sum_{i=1}^{N}\left(\pi_{t}-\pi^{*}\right)^{2}} .
$$

If only one specification of the model is applied to the above data generating process,

$$
\pi_{t}-\pi^{*}=\beta\left(\pi_{t-1}-\pi^{*}\right)+\varepsilon_{t} \text { for all } t,
$$

the estimated inertia of the inflation, defined by $\hat{\beta}$, is given by the following well-known formula.

$$
\begin{gathered}
\hat{\beta}=\frac{\sum_{i=1}^{N}\left(\pi_{t}-\pi^{*}\right)\left(\pi_{t-1}-\pi^{*}\right)}{\sum_{i=1}^{N}\left(\pi_{t}-\pi^{*}\right)^{2}}=\frac{\sum_{i=1}^{T}\left(\pi_{t}-\pi^{*}\right)\left(\pi_{t-1}-\pi^{*}\right)+\sum_{i=T+1}^{N}\left(\pi_{t}-\pi^{*}\right)\left(\pi_{t-1}-\pi^{*}\right)}{\sum_{i=1}^{T}\left(\pi_{t}-\pi^{*}\right)^{2}+\sum_{i=T+1}^{N}\left(\pi_{t}-\pi^{*}\right)^{2}} \\
=\frac{\sum_{i=1}^{T}\left(\pi_{t}-\bar{\pi}\right)\left(\pi_{t-1}-\bar{\pi}\right)+\sum_{i=T+1}^{N}\left(\pi_{t}-\pi^{*}\right)\left(\pi_{t}-\pi^{*}\right)+T\left(\bar{\pi}-\pi^{*}\right)^{2}}{\sum_{i=1}^{T}\left(\pi_{t}-\bar{\pi}\right)^{2}+\sum_{i=T+1}^{N}\left(\pi_{t}-\pi^{*}\right)^{2}+T\left(\bar{\pi}-\pi^{*}\right)^{2}} \\
=\frac{\sum_{i=1}^{T}\left(\pi_{t}-\bar{\pi}\right)^{2}}{Z} \hat{\alpha}+\frac{\sum_{i=T+1}^{N}\left(\pi_{t}-\pi^{*}\right)^{2}}{Z} \hat{\alpha}+\frac{T\left(\bar{\pi}-\pi^{*}\right)^{2}}{Z} \\
=\hat{\alpha} \frac{Z-T\left(\bar{\pi}-\pi^{*}\right)^{2}}{Z}+\frac{T\left(\bar{\pi}-\pi^{*}\right)^{2}}{Z}=\hat{\alpha}+(1-\hat{\alpha}) \frac{T\left(\bar{\pi}-\pi^{*}\right)^{2}}{Z}>\hat{\alpha} .
\end{gathered}
$$

Therefore, inflation inertia tends to be overestimated when the inflation target has been reduced during the sample period. 